\title{
Enraizamento de estacas da baunilheira (Orchidaceae)
}

\section{Rooting of cuttings of vanilla plant (Orchidaceae)}

\author{
Maria das Dôres David Silva ${ }^{1}$; Moacir Pasqual2²; Flávio Pereira Silva ${ }^{3}$; \\ José Maria Moreira Dias ${ }^{4}$; Aparecida Gomes de Araujo ${ }^{5}$
}

\section{Resumo}

\begin{abstract}
A baunilheira (Vanilla planifolia) é uma planta pouco explorada comercialmente, devido ao emprego de tecnologias de baixa eficiência para a produção de mudas. Assim sendo, realizou-se o presente trabalho com o objetivo de estudar o efeito de diferentes substratos, no enraizamento adventício de estacas retiradas de diferentes posições na planta. Estacas com $20 \mathrm{~cm}$ de comprimento, duas gemas e uma folha, tomadas na haste da planta, em cinco posições subseqüentes, a partir do ápice caulinar foram plantadas em diferentes substratos: 1) Meio líquido formado pela solução nutritiva de Clark acrescida de 2,5 $\mathrm{mg} \mathrm{L}^{-1} \mathrm{de}$ AIB, sendo acondicionado em caixas de isopor com capacidade para 1,5L revestidas, internamente, com sacola plástica transparente e vedadas com tampa própria. As tampas foram perfuradas para introdução das estacas plantadas na orientação vertical normal, com uma gema imersa na solução. O arejamento contínuo do meio líquido foi realizado com o auxílio de um compressor de ar. 2) Substrato sólido (areia, casca de arroz carbonizada, solo e esterco bovino curtido, em proporções iguais de volume), acondicionado em tubetes de polipropileno com capacidade para 0,28L. 3) Pré-enraizamento das estacas em meio líquido (20 dias antes do plantio), e posterior transferência das mesmas para tubetes contendo substrato sólido. As estacas plantadas no substrato sólido foram mantidas sob condições de nebulização intermitente controlada por um timer. Após 90 dias de cultivo, verificou-se uma porcentagem de estacas enraizadas na ordem de $98 \%$ a $100 \%$, independente do tratamento. Brotações maiores e mais vigorosas foram obtidas em estacas plantadas diretamente no substrato sólido. O enraizamento adventício de estacas e a formação de mudas de baunilheira foram favorecidos quando as estacas foram obtidas da posição P2 (compreendida entre 20 a $40 \mathrm{~cm}$ do ápice) e plantadas em substrato sólido, em casa de vegetação com sistema de nebulização intermitente.
\end{abstract}

Palavras-chave: Vanilla planifolia, propagação, estaquia, substrato, solução nutritiva

\begin{abstract}
The vanilla plant (Vanilla planifolia) could have a higher commercial production but there are problems in the efficiency of propagation. The present work was conducted with the aim of studying the effect of different substrates, in the adventitious rooting of cuttings taken at five heights in the plant stem. The cuttings were $20 \mathrm{~cm}$ long and had two buds and one leaf and were planted in: 1) Liquid medium formed by Clark's nutrient added of $2.5 \mathrm{mg} \mathrm{L}^{-1}$ of IBA placed in plastic foam box with a capacity of $1.5 \mathrm{~L}$ lined inside with transparent plastic bag and lidded with proper lid. 2) Solid substrate formed by the mixture of sand, carbonized rice husk, soil and cured cow manure in equal proportions of volume, they
\end{abstract}

${ }^{1}$ Departamento de Engenharia Florestal. Universidade Federal de Viçosa, Viçosa, MG.

2 Departamento de Agricultura. Universidade Federal de Lavras, Lavras, MG. E-mail: mpasqual@ufla.br.

3 Empresa de Pesquisa Agropecuária de Minas Gerais - EPAMIG, Viçosa, MG.

${ }^{4}$ Departamento de Fitotecnia. Universidade Federal de Viçosa, Viçosa, MG.

5 Departamento de Agricultura. Universidade Federal de Lavras. 37200-000, Lavras, MG.

Autor para correspondência 
being placed in rigid polypropylene with a capacity of $0.28 \mathrm{~L}$. 3) Pre-rooting of the cuttings in liquid medium ( 20 days before planting), and later transferred into seedling tubes containing solid substrate. The cuttings planted in the solid substrate were maintained under intermittent mist condition controlled by a timer. After 90 days, the percentage of rooting was of $98-100 \%$, regardless of the treatment. Larger and more vigorous sproutings were obtained from cuttings planted directly into solid substrate. Adventitious rooting of cuttings and formation of new vanilla cuttings occurred, when the cuttings were obtained from position P2 (ranging between 20 to $40 \mathrm{~cm}$ in stem height) and planted in solid substrate in greenhouse with intermittent misting system.

Key words: Vanilla planifolia, propagation, cutting, substrate, nutritious solution

\section{Introdução}

Dentre as orquidáceas cultivadas, a baunilheira (Vanilla sp) merece destaque, não somente pelo seu valor como espécie ornamental, mas, principalmente, pelas qualidades que apresenta, como planta aromática. Das espécies conhecidas, Vanilla planifolia Andrews éuma das mais cultivadas comercialmente em regiões tropicais, devido à qualidade e ao elevado teor de vanilina produzido em seus frutos (KALIMUTHU; SENTHILKUMAR; MURUGALATHA, 2006).

Tradicionalmente, é propagada pelo método da estaquia, a partir de estacas caulinares obtidas pelo seccionamento da haste da planta. No entanto, este método de propagação não é econômico, (devido à alta taxa de mortalidade das estacas) e também tem a desvantagem de ser moroso (KALIMUTHU; SENTHILKUMAR; MURUGALATHA, 2006).

Em plantações comerciais de orquídeas, é importante ponderar sobre as vantagens do emprego da estaquia a qual permite a transferência total de ganhos genéticos para os indivíduos da nova geração, além de apresentar maior uniformidade entre eles. Vários fatores influenciam direta ou indiretamente, a rizogênese em estacas. Dentre eles, o genótipo em estudo, o tipo de estaca, o ambiente de enraizamento, além da presença de indutores e inibidores de enraizamento (HARTMANN; KESTER; DAVIS JÚNIOR, 1997). Esses mesmos autores, afirmam ser indispensável um nível endógeno ótimo de auxina nas estacas para a iniciação do processo rizogênico. Estando a auxina endógena em menor nível na estaca, é necessário aplicar auxina sintética, a qual é capaz de otimizar o enraizamento adventício da estaca. Segundo estes autores, as auxinas sintéticas mais empregadas são ácido indol butírico (AIB), ácido naftaleno acético (ANA) e ácido 2,4-diclorofenoxiacético (2,4-D). Dentre estes, o AIB apresenta menor mobilidade e maior estabilidade química no interior da estaca, sendo uma das auxinas mais empregadas, por possuir alta atividade, faixa maior de concentrações não fitotóxicas e ser efetiva em muitas espécies (LORETI; HARTMANN, 1964).

A seleção do substrato deve levar em conta os aspectos relacionados ao manejo, custo, finalidade, reprodutibilidade e disponibilidade. Nesse sentido, a solução nutritiva se apresenta como um substrato promissor para as Orchidaceaes, além de fornecer macro e micronutrientes em concentrações ideais para a nutrição da planta. $\mathrm{O}$ emprego desta metodologia na produção de mudas por estaquia tem sofrido adaptações e vem sendo utilizada em clonagem de espécies como eucalipto (ASSIS, 2002; SCARASSATI, 2003; SILVA, 1998; XAVIER, 2002), tomateiro (FERNANDES, 2004) e outras espécies, como Swainsoma formosus, Rosa banksial, Bankisia ericifolia, Daphane odora e Grevillea spp. (WILKINSON, 1994 apud SILVA, 1998).

Neste trabalho, objetivou-se comparar a eficiência de diferentes substratos (líquido, sólido e líquido + sólido) na formação de mudas de Vanilla planifolia, a partir do enraizamento adventício de estacas retiradas de diferentes posições na planta. 


\section{Material e Métodos}

O experimento foi conduzido, no período de novembro de 2006 a fevereiro de 2007, em casas de vegetação com $50 \%$ de sombreamento, nas dependências do Departamento de Fitotecnia/Setor de Fruticultura da Universidade Federal de Viçosa, em Viçosa, Minas Gerais.

Os tratamentos envolvendo substrato sólido foram desenvolvidos em casa de vegetação equipada com sistema automatizado de nebulização, o qual permitiu teor de umidade relativa mínimo de $85 \%$, nos intervalos entre irrigações. Os tratamentos envolvendo meio líquido foram mantidos em casa de vegetação (50\% de luminosidade), na ausência de irrigação aérea.

As estacas foram coletadas de plantas de baunilheira (Vanilla planifolia) que se encontravam vegetando naturalmente em matas ciliares localizadas em área pertencente à Universidade Federal de Viçosa situada no município de Florestal, MG. Destas plantas foram retiradas estacas com $50 \mathrm{~cm}$ de comprimento, as quais foram plantadas em recipiente com capacidade para 5,0 L contendo substrato formulado com mistura de areia fina lavada, subsolo, casca de arroz carbonizada e esterco bovino curtido, na proporção de 1:1:1:1 (v/v). As plantas foram mantidas em condições de telado com 50\% de sombreamento. Durante o cultivo, as plantas foram monitoradas periodicamente, visando averiguar a ocorrência de pragas, doenças e plantas daninhas. Não houve necessidade de intervenção com produtos fitossanitários, nem de adubação, realizando-se apenas a capina manual nos recipientes.

As matrizes foram cultivadas durante 30 meses. Delas foram coletadas as estacas empregadas neste trabalho, as quais foram identificadas de acordo com a posição em que foram retiradas na haste da planta (5 estacas por planta). A primeira estaca recebeu a denominação de estaca apical (posição P1, $20 \mathrm{~cm}$ iniciais) e foi constituída pelo ápice caulinar, duas gemas e uma folha totalmente expandida mantida na primeira gema abaixo do ápice. Sucessivamente, foram tomadas as estacas das demais posições até a posição P5. Estaca P2 (compreendida entre $20-40 \mathrm{~cm}$ do ápice), P3 (entre 40-60 cm do ápice), P4 (entre 60$80 \mathrm{~cm}$ do ápice) e P5 (entre $80-100 \mathrm{~cm}$ do ápice). As estacas foram preparadas com, aproximadamente, $20 \mathrm{~cm}$ de comprimento, contendo, no mínimo, dois nós. Quando presentes, foram eliminadas a folha e a raiz do nó da gema da base da estaca, que ficou imersa no substrato, enquanto a folha da gema distal foi mantida. Inicialmente, as estacas foram tratadas com fungicida (Mancozeb $\mathrm{BR}^{\circledR}, 3 \mathrm{~g} \mathrm{~L}^{-1}$ ) visando o controle da contaminação superficial. Posteriormente, foram lavadas para eliminar o resíduo do fungicida e deixadas à sombra para escorrer o excesso de água.

O ápice das estacas recebeu um corte transversal, sendoesteimersoemparafinalíquida,deformaaevitar perda de água e contaminação por microrganismos na superfície cortada. A base da estaca foi cortada em bisel para aumentar a área de absorção de água e nutrientes e, também nos tratamentos em meio líquido, para evitar que a mesma ficasse totalmente apoiada no fundo do recipiente. As estacas foram plantadas na orientação vertical normal, deixando expostas apenas uma gema e uma folha e, quando presente, o ápice caulinar.

Neste trabalho, empregaram-se dois tipos de recipiente, conforme o tratamento aplicado às estacas. Nos tratamentos envolvendo substrato sólido, foram empregados tubetes de polipropileno rígido com capacidade para $0,28 \mathrm{~L}$, contendo substrato sólido formado pela mistura de areia fina lavada, subsolo, casca de arroz carbonizada e esterco bovino curtido, na proporção de 1:1:1:1 (v/v). Nos tratamentos com meio líquido, o recipiente utilizado foi caixa de isopor de formato quadrado com capacidade para $1,5 \mathrm{~L}$ revestida internamente com uma sacola plástica transparente, aderida à parede do recipiente, a fim de evitar o vazamento da solução. As caixas foram vedadas com tampas próprias de isopor e perfuradas para a introdução da mangueira de aeração e das estacas. Todas as frestas das 
tampas foram vedadas com algodão, visando evitar a entrada de luz na solução e, conseqüentemente, o crescimento indesejável de algas.

O meio líquido de propagação foi constituído por solução hídrica contendo $2,5 \mathrm{mg} \mathrm{L}^{-1}$ de ácido indolbutírico (AIB) adicionado na solução nutritiva de Clark (1975) modificada, cuja formulação encontra-se na Tabela 1. A solução final teve o pH ajustado para 5,8 $\pm 0,1$ e as alíquotas distribuídas noas caixas foram arejadas de forma contínua, durante todo o período experimental. $\mathrm{O}$ ar comprimido foi fornecido às soluções por meio de uma mangueira plástica transparente, com $0,5 \mathrm{~cm}$ de calibre e possuindo, em uma das extremidades, uma agulha hipodérmica para captação do ar da mangueira mestre adaptada a um compressor de ar (pressão de $30 \mathrm{lb} \mathrm{pol}^{-2}$ ).

Tabela 1. Concentrações de macro e micronutrientes contidas na solução nutritiva de Clark (1975), utilizada no enraizamento adventício de estacas de Vanilla planifolia.

\begin{tabular}{lccc}
\hline & \multicolumn{2}{c}{ MACRONUTRIENTES } & \multicolumn{2}{c}{ MICRONUTRIENTES } \\
\hline & Concentração $\left(\mathbf{m m o l ~ L}^{-1}\right)$ & \multicolumn{2}{c}{ Concentração $\left(\boldsymbol{\mu m o l ~ \mathbf { L } ^ { - 1 } )}\right.$} \\
\hline $\mathrm{N}-\mathrm{NO}_{3}^{-}$ & 7,26 & $\mathrm{~B}$ & 19 \\
$\mathrm{~N}-\mathrm{NH}_{4}$ & 0,9 & $\mathrm{Cu}$ & 0,5 \\
$\mathrm{P}-\mathrm{H}_{2} \mathrm{PO}_{4}^{-}$ & 0,069 & $\mathrm{Mn}$ & 40 \\
$\mathrm{~K}^{+}$ & 1,8 & $\mathrm{Mo}$ & 7 \\
$\mathrm{Ca}^{++}$ & 2,56 & $\mathrm{Zn}$ & 0,086 \\
$\mathrm{Mg}^{++}$ & 0,6 & & 2 \\
$\mathrm{~S}-\mathrm{SO}_{4}^{--}$ & 0,6 & & \\
\hline
\end{tabular}

Durante a condução do experimento foram realizadas trocas periódicas das soluções a cada 30 dias, por outra de formulação idêntica a anterior. Nos intervalos de troca da solução, completou-se o volume com água, quando necessário. Ao final de 90 dias, o experimento foi avaliado.

Neste trabalho, foram disponibilizadas às estacas três condições diferentes para o enraizamento. $\mathrm{Na}$ condição de enraizamento $1(\mathrm{C} 1)$, as estacas foram plantadas em tubetes contendo substrato sólido e mantidas em casa de vegetação, com nebulização controlada, durante todo período experimental, que foi de 90 dias. Na condição de enraizamento 2 (C2), as estacas foram plantadas e mantidas em substrato líquido, com arejamento durante 20 dias, tempo necessário para a emissão e crescimento das raízes até, no máximo, $2 \mathrm{~cm}$ de tamanho. Em seguida, as estacas enraizadas foram transplantadas para substrato sólido, a exemplo da condição $\mathrm{C} 1$, onde permaneceu durante os últimos 70 dias do período de enraizamento. A terceira condição de enraizamento (C3) envolveu o emprego de solução hídrica para o enraizamento das estacas e formação da muda, durante os 90 dias em que o experimento foi conduzido. Nesta condição, empregaram-se caixas de isopor, protegidas internamente, com plástico transparente, para o acondicionamento da solução. Este tratamento, bem como a primeira etapa da condição C2, foi conduzido na ausência de irrigação aérea, em casa de vegetação equipada com compressor de ar, para o arejamento das soluções.

Foi empregado o delineamento inteiramente casualizado, no esquema fatorial $5 \times 3$, perfazendo 15 tratamentos constituídos pelas combinações entre os fatores: posição das estacas, em cinco níveis: P1, P2, P3, P4 e P5, e tipo de substrato (ou condição de enraizamento), em três níveis: substrato sólido, meio líquido e pré-enraizamento em meio líquido com posterior transplantio para substrato sólido. 
Empregaram-se três repetições e a unidade experimental foi constituída por oito estacas, totalizando 45 unidades experimentais e 360 estacas. O valor de cada unidade experimental foi obtido com base na média dos valores encontrados em todas as estacas que a compuseram, no momento da análise.

Ao final do experimento, foi avaliada a formação e o desenvolvimento da muda, tomando-se por base as seguintes características: porcentagem de estacas enraizadas, comprimento médio de raiz, volume médio de raiz, massa seca da raiz, porcentagem de estacas brotadas, altura de brotos e massa seca de brotos.

Altura de brotos - esta medida foi tomada utilizando-se fita métrica, graduada em $\mathrm{mm}$, de material flexível, que permitiu avaliação mais precisa do comprimento do broto, uma vez que o seu crescimento não é retilíneo. $O$ broto foi medido a partir do seu ponto de inserção com a axila da folha original, até o ápice da folha semi-expandida mais alta.

- Comprimento de raiz - foi utilizada régua milimetrada para medição dos comprimentos de todas as raízes formadas, obtendo-se, assim, o comprimento total de raiz por estaca. $\mathrm{O}$ valor médio representativo do comprimento de raiz, por repetição, foi obtido pela média aritmética dos valores encontrados nas estacas sobreviventes.

Volume de raízes - este procedimento foi realizado com o auxílio de uma proveta de vidro graduada com precisão de $1 \mathrm{~mL}$. Foram coletados os sistemas radiculares formados pelas estacas componentes da repetição e avaliado o seu volume e, então, obtida a média aritmética representativa da repetição em cada tratamento.

Massa seca da parte aérea e da raiz - para determinação da massa seca, o material foi acondicionado em saco de papel e colocado em estufa com circulação forçada de ar, à temperatura de $65^{\circ} \mathrm{C}$ até atingir massa constante (aproximadamente 10 dias), ocasião em que foi realizada a pesagem em balança eletrônica com precisão de três casas decimais.

Para cada variável analisada, os dados obtidos foram submetidos à análise de variância para $\mathrm{o}$ arranjo fatorial ( $5 \times 3)$, no delineamento inteiramente casualizado, com três repetições, empregando-se o teste F.

Separadamente, e para cada fator estudado, as médias dos tratamentos foram comparadas pelo teste de Duncan, a 5\% de probabilidade. As análises estatísticas foram realizadas no Programa SAEG (RIBEIRO JÚNIOR, 2001).

\section{Resultados e Discussão}

Não houve interação significativa entre os tratamentos, para nenhuma das características estudadas. Com exceção da porcentagem de enraizamento, todas as variáveis revelaram diferenças significativas para os fatores posição da estaca e condição de plantio, separadamente (Tabelas 2 e 3 ).

Assim, os dados relativos às posições de retirada das estacas na planta e às condições de plantio foram analisados separadamente, sendo as médias comparadas pelo teste de Duncan (Tabelas 2 e 3 ).

Com relação à porcentagem de enraizamento das estacas, esta variou de $98,3 \%$ a $100 \%$ independente da posição em que a estaca foi retirada na haste e da condição em que a mesma foi cultivada (substrato sólido ou meio líquido), conforme pode ser observado nas Tabelas 2 e 3. Os resultados obtidos sugerem que os níveis endógenos de auxina, associados ao conteúdo nutricional já existentes nas estacas foram suficientes para permitir a alta porcentagem de enraizamento observada em todos os substratos utilizados. 
Tabela 2. Médias observadas para as variáveis enraizamento (ENR), comprimento total médio de raízes (CTR), volume médio de raízes (VOLR), massa seca de raízes (MSR), brotação (BRT), altura de brotos (ALTB) e massa seca de brotos (MSB), nas estacas de Vanilla planifolia, em função da posição de sua retirada na planta, aos 90 dias após o estaqueamento.

\begin{tabular}{cccccccc}
\hline & \multicolumn{7}{c}{ Variáveis analisadas } \\
\cline { 2 - 8 } Posição & ENR $(\%)$ & $\begin{array}{c}\text { CTR } \\
(\mathrm{cm})\end{array}$ & VOLR $(\mathrm{mL})$ & $\begin{array}{c}\text { MSR } \\
(\mathrm{g})\end{array}$ & BRT $(\%)$ & ALTB $(\mathrm{cm})$ & $\begin{array}{c}\text { MSB } \\
(\mathrm{g})\end{array}$ \\
\hline P1 & $100,00 \mathrm{a}$ & $16,04 \mathrm{c}$ & $0,750 \mathrm{c}$ & $0,0412 \mathrm{c}$ & $79,17 \mathrm{~b}$ & $4,39 \mathrm{~b}$ & $0,059 \mathrm{c}$ \\
P2 & $100,00 \mathrm{a}$ & $20,23 \mathrm{~b}$ & $0,944 \mathrm{~b}$ & $0,0534 \mathrm{~b}$ & $94,44 \mathrm{a}$ & $9,65 \mathrm{a}$ & $0,228 \mathrm{~b}$ \\
P3 & $98,61 \mathrm{a}$ & $25,03 \mathrm{a}$ & $1,159 \mathrm{a}$ & $0,0696 \mathrm{a}$ & $97,22 \mathrm{a}$ & $10,28 \mathrm{a}$ & $0,267 \mathrm{a} \mathrm{b}$ \\
P4 & $100,00 \mathrm{a}$ & $21,79 \mathrm{a} \mathrm{b}$ & $1,035 \mathrm{a} \mathrm{b}$ & $0,0623 \mathrm{a} \mathrm{b}$ & $97,22 \mathrm{a}$ & $11,63 \mathrm{a}$ & $0,299 \mathrm{a}$ \\
P5 & $98,61 \mathrm{a}$ & $21,39 \mathrm{~b}$ & $1,014 \mathrm{a} \mathrm{b}$ & $0,0619 \mathrm{a} \mathrm{b}$ & $91,67 \mathrm{a}$ & $9,65 \mathrm{a}$ & $0,263 \mathrm{a} \mathrm{b}$ \\
\hline
\end{tabular}

P1 (estacas apicais com 20cm), P2 (entre 20-40 cm do ápice), P3 (entre 40-60 cm do ápice), P4 (entre 60-80 cm do ápice) e P5 (entre 80-100 cm do ápice).

Médias seguidas pela mesma letra, na coluna, não diferem entre si, significativamente, pelo teste de Duncan ( $\mathrm{P}>$ $0,05)$.

Tabela 3. Médias observadas para as variáveis enraizamento (ENR), comprimento total de raízes (CTR), volume médio de raízes (VOLR), massa seca de raízes (MSR), brotação (BRT), altura de brotos (ALTB) e massa seca de brotos (MSB), nas estacas de Vanilla planifolia, em função da condição de enraizamento das estacas, aos 90 dias após o estaqueamento.

\begin{tabular}{cccccccc}
\hline & \multicolumn{7}{c}{ Variáveis analisadas } \\
\cline { 2 - 7 } Condição & $\begin{array}{c}\text { ENR } \\
(\%)\end{array}$ & CTR $(\mathrm{cm})$ & VOLR $(\mathrm{mL})$ & $\begin{array}{c}\text { MSR } \\
(\mathrm{g})\end{array}$ & $\begin{array}{c}\text { BRT } \\
(\%)\end{array}$ & ALTB $(\mathrm{cm})$ & $\begin{array}{c}\text { MSB } \\
(\mathrm{g})\end{array}$ \\
\hline $\mathrm{C} 1$ & $98,33 \mathrm{a}$ & $20,227 \mathrm{~b}$ & $0,900 \mathrm{~b}$ & $0,053 \mathrm{~b}$ & $97,50 \mathrm{a}$ & $10,204 \mathrm{a}$ & $0,293 \mathrm{a}$ \\
$\mathrm{C} 2$ & $100,00 \mathrm{a}$ & $22,992 \mathrm{a}$ & $1,133 \mathrm{a}$ & $0,066 \mathrm{a}$ & $89,17 \mathrm{~b}$ & $6,467 \mathrm{~b}$ & $0,159 \mathrm{c}$ \\
$\mathrm{C} 3$ & $100,00 \mathrm{a}$ & $19,474 \mathrm{~b}$ & $0,908 \mathrm{~b}$ & $0,053 \mathrm{~b}$ & $89,17 \mathrm{~b}$ & $10,180 \mathrm{a}$ & $0,218 \mathrm{~b}$ \\
\hline
\end{tabular}

C1- substrato sólido; C2- substrato líquido + sólido e C3- solução líquida.

Médias seguidas pela mesma letra, na coluna, não diferem entre si, significativamente, pelo teste de Duncan $(\mathrm{P}>$ $0,05)$.

Os resultados obtidos neste experimento, corroboram com aqueles obtidos por Carvalho et al. (2007), os quais concluíram que o enraizamento de carqueja (Baccharis trimera Less. DC.) não é influenciado pelo tipo de substrato e nem pela posição da estaca na planta matriz.

Verificou-se pequena diferença entre os dados obtidos para o enraizamento de estacas, fato este que pode ser explicado pela uniformidade do material botânico utilizado, no que se refere aos aspectos de idade fisiológica das brotações, ambiente de cultivo e tratos culturais fornecidos às matrizes doadoras de estacas.
Os resultados observados para comprimento médio de raiz, volume médio de raiz e massa seca de raiz estão apresentados nas Tabelas 2 e 3.

No que se refere à posição de retirada das estacas na haste da planta, foi observado que a posição 1, que por si só, são de natureza herbácea, apresentou os resultados menos favoráveis para essas características (Tabela 2).

Os resultados obtidos refletem as conseqüências do atraso no tempo de enraizamento observado para as estacas apicais (P1) que sofreram murcha do ápice, com posterior brotação da gema subseqüente, 
apresentando um enraizamento mais tardio (em torno de 15 dias) do que as estacas das demais posições.

Considerando ser a baunilha uma planta epífita trepadeira, nota-se a presença de raízes adventícias aéreas em sua haste, que promovem a fixação da planta ao suporte. Neste trabalho, observou-se que a emissão dessas raízes ocorre nas adjacências da gema situada a partir do terceiro internódio, contado do ápice caulinar, que, neste estudo, se refere à posição P2.

Diante dessas informações, verifica-se que os resultados obtidos refletem a resposta fisiológica da espécie às condições de plantio em que as estacas foram submetidas, indicando que as posições P2 a $\mathrm{P} 5$ proporcionaram os melhores resultados às características em análise (Tabela 2).

Observou-se que o pré-enraizamento em meio líquido, com posterior plantio em substrato sólido (C2), apresentou os melhores resultados para a formação e o desenvolvimento do sistema radicular (Tabela 3). Uma possível explicação para esta resposta pode estar na presença de auxina no meio líquido, promovendo uma maior velocidade na formação e crescimento das raízes. Com a emissão das raízes, as estacas foram transferidas para o substrato sólido, que forneceu os nutrientes minerais e matéria orgânica essenciais ao franco desenvolvimento do sistema radicular.

As estacas mantidas em meio líquido durante todo o período experimental (C3) puderam contar com condições semelhantes àquelas experimentadas pelas estacas da $\mathrm{C} 2$ de plantio, porém, os valores obtidos para as variáveis analisadas, em $\mathrm{C} 3$, foram menores (Tabela 3). Esta resposta parece indicar que a presença constante de auxina no meio de enraizamento, e de cultivo posterior, influenciou negativamente o crescimento e o desenvolvimento das raízes. Este comportamento reflete as afirmativas de Hartmann, Kester e Davis Júnior (1997) ao citarem que, quando a auxina é aplicada em estacas, ocorre aumento da sua concentração, o que produz efeito estimulador de raízes até um ponto máximo, a partir do qual qualquer acréscimo do nível de auxina torna-se inibitório. Notou-se que, no meio líquido, foi sempre disponibilizada às estacas a mesma concentração de auxina, porém, a absorção contínua, pela estaca, pode ter provocado aumento supra-ótimo nos níveis endógenos da mesma. Comparando-se os resultados obtidos para $\mathrm{C} 1$, em que as estacas foram plantadas diretamente no substrato sólido, com C2, em que houve pré-enraizamento das estacas em meio líquido, verificou-se, nas estacas $\mathrm{C} 2$, incremento de $14 \%$ para a variável comprimento de raiz, $26 \%$ para volume de raiz e $24 \%$ para massa seca de raiz.

Diante dos resultados obtidos, a escolha da condição de plantio é um importante aspecto a ser considerado. Para atender às necessidades impostas pela $\mathrm{C} 2$, em sua primeira etapa, são registrados alguns custos, tais como: compressor de ar e acessórios para disponibilizar o ar comprimido aos recipientes, medidor de $\mathrm{pH}$, deionizador de água, balança de precisão e o contínuo suprimento de reagentes químicos, nutrientes minerais e auxina sintética, além de pessoal treinado para a sua execução.

A condição 1, plantio direto no substrato sólido, exige casa de vegetação com sistema de nebulização intermitente e disponibilidade de materiais para composição do substrato que, por sua própria natureza, oferece os nutrientes necessários à manutenção das estacas, durante o período de enraizamento adventício e formação da muda. Além disso, não requer mão-de-obra especializada para desenvolver as atividades impostas por esta condição.

Considerando os incrementos médios obtidos em $\mathrm{C} 2$, que foram pequenos, com as facilidades apresentadas pela condição 1 , parece mais viável indicar o plantio das estacas de baunilha diretamente no substrato sólido em casa de vegetação com condições ambientais controladas.

Estacas enraizadas na condição 3, além de não oferecerem vantagens sobre aquelas que enraizaram 
nas duas outras condições (1 e 2), apresentam a desvantagem de formarem mudas com raízes nuas, o que irá repercutir, negativamente, no índice de pegamento das mesmas, quando forem transplantadas para condições de campo.

Para as variáveis porcentagens de brotação e altura de brotos, foi possível verificar a influência da posição em que a estaca foi extraída na haste da planta e, nesse caso, a estaca apical (P1) apresentou as menores médias, que diferiram das demais posições pelo teste de Duncan $(\mathrm{P}<0,05)$. Embora as posições de $\mathrm{P} 2$ a $\mathrm{P} 5$ não tenham sido estatisticamente diferentes, observou-se que as estacas tomadas na posição P4 formaram brotos maiores e mais vigorosos.

As diferenças observadas entre as médias dos tratamentos da posição $\mathrm{P} 1$ e da posição $\mathrm{P} 4$, que apresentaram as maiores médias observadas, refletiram incremento de $22,8 \%$ para porcentagem de brotação, $164,92 \%$ para altura de brotos e $406,78 \%$ para massa seca de brotos.

As estacas da posição P1 apresentaram, durante certo período de tempo, aparente paralisação no crescimento do seu ápice que começou a murchar. Posteriormente, iniciou-se a brotação da gema subseqüente, que produziu a parte aérea da estaca, formando a nova muda. Deve-se considerar também que as estacas apicais eram mais tenras e menos vigorosas que as demais, conseqüentemente, possuidoras de menor quantidade de reservas nutricionais para a formação e o crescimento do broto.

Diante disso, é possível inferir que as estacas apicais são capazes de enraizar e formar novas mudas, porém, deverão formar um grupo à parte que estará em condições de plantio no campo algum tempo após as demais estacas obtidas a partir da posição P2. Sugerem-se a obtenção e o estaqueamento das estacas apicais previamente à das demais, como forma de uniformizar o tamanho e o desenvolvimento das mudas de baunilheira obtidas pelo método da estaquia.
Observou-se, para as variáveis porcentagens de brotações, altura e massa seca de brotos, que os resultados obtidos foram favorecidos pelo plantio das estacas diretamente em substrato sólido (condição C1), como mostra a Tabela 3.

As diferenças observadas entre as médias dos tratamentos da condição $\mathrm{C} 2$, que apresentaram resultados inferiores, e $\mathrm{C} 1$ refletiram um incremento de $9,34 \%$ para a porcentagem de brotação, 57,78\% para altura de brotos e $84,27 \%$ para massa seca de brotos. Pelos dados observados verifica-se que as médias encontradas para altura de brotos foram semelhantes entre os tratamentos da condição de plantio C1 e C3 (Tabela 3).

Esses resultados revelaram que a presença da auxina no substrato líquido de enraizamento promoveu efeito inibitório sobre o crescimento em altura dos brotos e, diretamente, afetou os resultados da massa seca de brotos. A auxina disponível no meio de enraizamento pode ter sido absorvida pela estaca, promovendo alteração no balanço endógeno citocinina/auxina que, neste caso, foi desfavorável ao desenvolvimento dos brotos, o que está de acordo com Skoog e Miller (1957).

Nicoloso, Fortunato e Fogaça (1999) estudando a influência da posição da estaca no ramo e do substrato no processo de enraizamento de estacas de fáfia (Pfaffia glomerata (Spreng.) Pedersen) relatam que estacas obtidas das porções medianas e basal apresentam maior capacidade de enraizamento e a combinação de solo + casca de arroz carbonizada é um substrato viável para a estaquia.

Salomão, Pereira e Duarte (2002) avaliando o desempenho de vários tipos de estacas, como material para formação de mudas de maracujazeiros doce (Passiflora alata Dryand.) e amarelo (P. edulis f. flavicarpa O. Deg.) observaram que estacas das posições basal e mediana apresentaram maior potencial de enraizamento e maior crescimento do sistema radicular em ambas espécies 


\section{Conclusões}

1. O enraizamento adventício de estacas e a formação de mudas de baunilheira podem ser favorecidos com utilização de estacas obtidas a partir da posição P2 (compreendida entre 20 a 40 $\mathrm{cm}$ do ápice).

2. As estacas podem ser plantadas diretamente no substrato sólido e mantidas em casa de vegetação com condições ambientais controladas.

\section{Referências}

ASSIS, T. F. Evolution of technology for cloning Eucalyptus in large scale. Guaíba: Klabin, 2002.

CARVALHO, R. I. N.; NOLASCO, M. A.; CARVALHO, T.; RIPKA, M.; GIUBLIN, L. M.; NEGRELLO, M.; SCHEFFER, M. C. Enraizamento de estacas de carqueja em função de diferentes substratos e posições do ramo em plantas masculinas e femininas. Scientia Agraria, Curitiba, v. 8, n. 3, p. 269-274, 2007.

CLARK, R. B. Characterization of phosphatase of intact morize roots. Journal of the Agricultural and Food Chemistry, Washington, v. 23, n. 3, p. 458-460, May./ Jun. 1975.

FERNANDES, A. A. Propagação vegetativa e cultivo do tomateiro em sistema hidropônico. 2004. Tese (Doutorado em Fitotecnia) - Universidade Federal de Viçosa, Viçosa.

HARTMANN, H. T.; KESTER, D. E.; DAVIS JÚNIOR; F. T. Plant propagation: principles and practices. 6.ed. New York: Englewood Clipps/Prentice Hall, 1997.

KALIMUTHU, K.; SENTHILKUMAR, R.; MURUGALATHA, N. Regeneration and mass multiplication of Vanilla planifolia Andr. - a tropical orchid. Current Science, Bangalore, v. 91, n. 10, p. 14011403, 2006.
LORETI, F.; HARTMANN, H. T. Propagation of olive trees by rooting leafy cuttings under mist. Proceedings American Society Horticultural Science, Alexandria, v. 85, p. 257-264, Dec. 1964.

NICOLOSO, F. T.; FORTUNATO, R. P.; FOGAÇA, M. A. F. Influência da posição da estaca no ramo sobre o enraizamento de Pfaffia glomerata (Spreng.) Pedersen em dois substratos. Ciência Rural, Santa Maria, v. 29, n. 2, p. 277-283, 1999.

RIBEIRO JÚNIOR, J. I. Análises estatísticas no SAEG. Viçosa: Ed. da UFV, 2001.

SALOMÃO, L. C. C.; PEREIRA, W. E.; DUARTE, R. C. C. Propagação por estaquia dos maracujazeiros doce (Passiflora alata Dryand.) e amarelo (P. edulis $\mathrm{f}$. flavicarpa O. Deg.). Revista Brasileira de Fruticultura, Jaboticabal, v. 24, n. 1, p. 163-167, 2002.

SCARASSATI, A. Avaliações ambiental e nutricional da produção de microcepas e microestacas de Eucalyptus grandis $x$ Eucalyptus urophylla em sistema hidropônico em casa de vegetação. 2003. Tese (Doutorado em Agronomia/Energia na Agricultura) - Faculdade de Ciências Agronômicas da Universidade Estadual de São Paulo, Botucatu.

SILVA, A. R. Enraizamento de estacas de Eucalyptus grandis via sistema hidropônico. 1998. Dissertação (Mestrado em Ciência Florestal) - Universidade Federal de Viçosa, Viçosa.

SKOOG, F.; MILLER, C. O. Chemical regulation of growth and organ formation in plant tissues cultured in vitro. Symposium of Society for Experimental Biology, Cambridge, v. 54, n. 11, p. 118-131, 1957.

XAVIER, A. Silvicultura clonal I: princípios e técnicas de propagação vegetativa. Viçosa: Ed. da UFV, 2002. (Caderno Didático, 92). 
